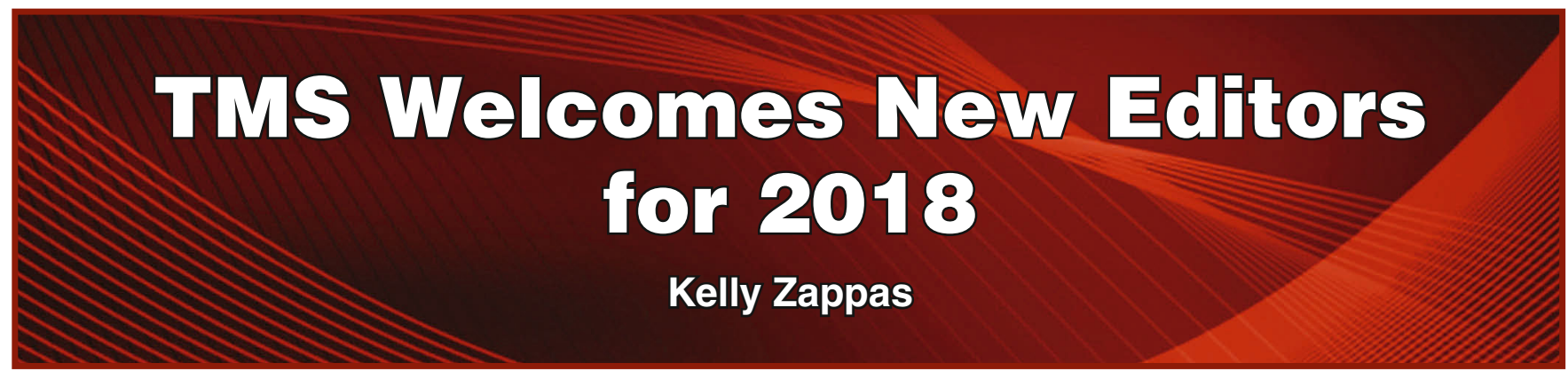

A need to replace dedicated, retiring editors and a desire to expand industrial coverage in JOM are the driving forces behind three new editor appointments to TMS journals in recent months.

Two long-time editors of the Metallurgical and Materials Transactions journals, Thaddeus (Ted) Massalski and Richard J. Fruehan, concluded their service to these publications in 2017. Massalski, who is professor emeritus of Materials Science, Engineering, and Physics at Carnegie Mellon University, had been an editor of Metallurgical and Materials Transactions A (MMTA) since 1981. Fruehan, U.S. Steel Professor of Materials Science and Engineering and co-director of the Center for Iron and Steelmaking Research at Carnegie Mellon University, also retired from his position at Metallurgical and Materials Transactions B (MMTB) at the end of 2017 after more than 30 years of service.

Amy Clarke, associate professor, metallurgical and materials engineering, at the Colorado School of Mines, took over Massalski's role as an editor of MMTA on December 1. Clarke, who has served as a key reader for MMTA, brings to the editorial team a background of experience in academic, government, and industrial settings.

"First, I am extremely honored to stand on the shoulders of giants to join the editorial board of MMTA," said Clarke. "I sincerely thank the outgoing editors for their years of dedication in making this journal what it is today. MMTA has published many classic works in physical metallurgy and materials science. It was the first journal I ever did a review for, and I feel a sense of obligation to ensure that its future builds upon its past."

Clarke is site director for the Center for Advanced Non-Ferrous Structural Alloys, a U.S. National Science Foundation Industry/University Cooperative Research Center addressing the physical metallurgy needs of industries working with non-ferrous structural alloys. The center has sites at the Colorado School of Mines and Iowa State University. Previously, Clarke was a scientist at Los Alamos National Laboratory in the Materials Science and Technology-Metallurgy Group, where she focused on making, measuring, and modeling metals during solidification.

Clarke has extensive experience as a TMS volunteer in

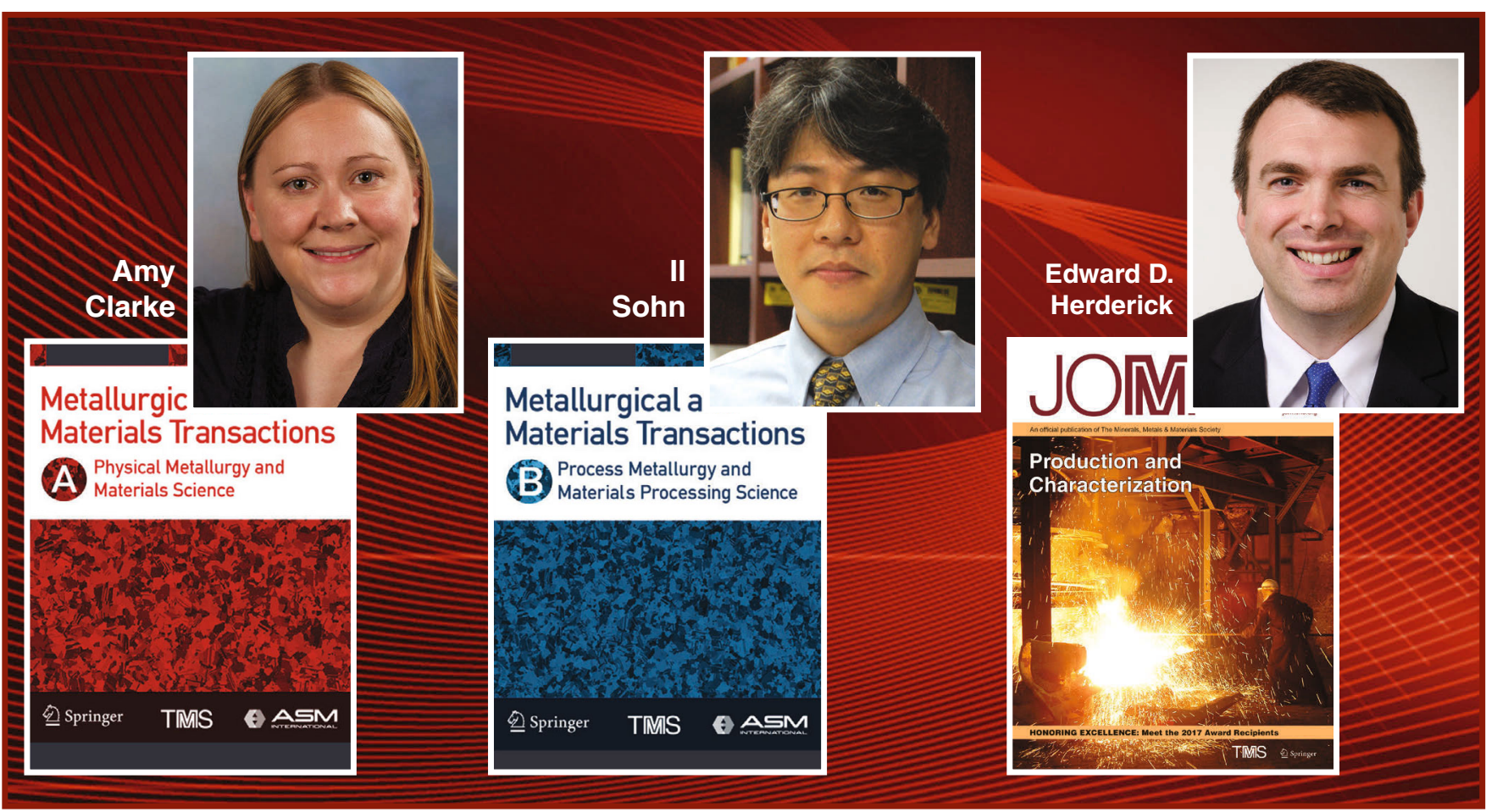


all aspects of the society. She is currently the Membership and Student Development Director on the TMS Board of Directors and served last year as the TMS representative to the program coordinating committee of the Materials Science \& Technology conference.

"In the coming years, I hope to make sure that MMTA continues to publish the highest quality contributions to our field, and remains the home for physical metallurgy and materials science," said Clarke. "Another goal is to reduce the time from submission to publication, while still providing the meaningful reviews to authors that MMTA is known for. I also hope to strategically promote 'virtual symposia,' or thematic collections on particular topics, which will be electronically linked."

Il Sohn, professor in the Department of Materials Science and Engineering at Yonsei University in South Korea, stepped into Fruehan's role as an editor of MMTB on January 1, with an acknowledgment of the contributions of past editors.

"Metallurgical and Materials Transactions $B$ has a rich history of publishing and disseminating knowledge in the broad field of metals and materials processing and is the prominent source for innovative ideas and solutions applicable to existing and developing industries," said Sohn. "I hope to ensure that the journal continues to be a platform for both ferrous and non-ferrous researchers."

Sohn's research focuses on understanding the fundamentals of high-temperature extractive metallurgy, from refining to continuous solidification of molten metal and developing next-generation eco-friendly and energyefficient extractive metallurgical processes. Sohn is also

\section{JEM Editorial Team Changes}

The Journal of Electronic Materials (JEM)

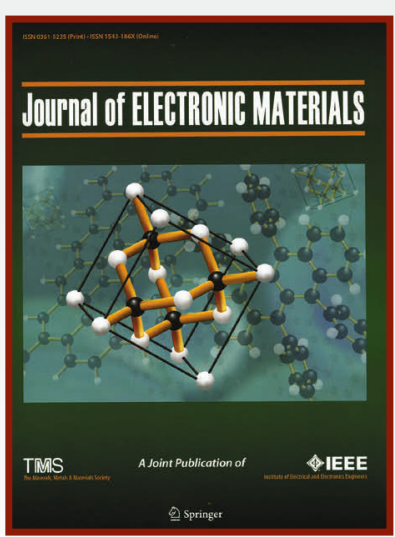

welcomes three new section editors to its editorial team, effective January 2018. They are: Wojciech Jadwisienczak, Ohio University; Manh-Huong Phan, University of South Florida; and Dan Ricinschi, Tokyo Institute of Technology, Japan.

JEM also congratulates John D. Baniecki, Fujitsu Laboratories, Japan, who will be moving from a section editor to senior editor position with the journal. Editor-in-Chief Shadi ShahedipourSandvik, SUNY Polytechnic Institute, and section editor Tom Bieler, Michigan State University, will continue in their current roles.

\section{Visit www.tms.org/Journals to learn}

\author{
more about submitting articles to
} the journals featured in this article.

associate director of Yonsei Engineering Research Park.

"With industry and academic experience in the international community for ferrous and non-ferrous metals processing, I hope to expand our existing pool of experts to ensure that the right people provide feedback to our authors at the right time after submission and solicit comprehensive reviews on topics critical to our field," said Sohn. "I am grateful for this opportunity to serve my colleagues and to have an opportunity to work with our principal editor in continuing the success of the journal."

$J O M$ also added to its editorial team when Edward D. Herderick, Director of Additive Manufacturing at The Ohio State University Center for Design and Manufacturing Excellence, stepped into the new position of Industrial Editor in November 2017. In this role, Herderick is charged with improving outreach to potential industry authors and helping to expand the journal's coverage of industry-relevant topics.

"I love the mix of industry, academia, and national labs represented in TMS's membership," said Herderick. "I'd like to help industrial members engage academics and vice versa. These two groups often want to work together, but they don't always know how."

Herderick has previously served as a JOM advisor and as a member of the TMS Board of Directors. Prior to working at Ohio State, Herderick spent his career in industry at companies such as $\mathrm{GE}, \mathrm{RP}+\mathrm{M}$, and the Edison Welding Institute.

"I have a wide industrial network," said Herderick. "And I'll bring my network to this position."

Herderick will work with special topic advisors to increase industrial representation in the journal, helping them to provide an appropriate level of industrial perspective and to frame their topics in a way that appeals to the broad JOM readership, including industry. He'll also help to recruit industrial contributors to write relevant reviews and research articles on topics of interest.

"When I served on the TMS Board of Directors, I was a vocal advocate for increased industrial engagement," said Herderick. "Now I'm happy to contribute to that goal as the JOM Industrial Editor."

Learn how to submit your work to any of these TMS journals through the TMS website at www.tms .org/Journals. TMS members can also read current and archived issues of all journals published by TMS by logging in to the TMS website and then selecting one of the journals listed on the Journals home page.

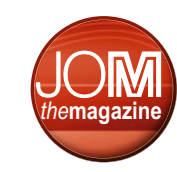

